\title{
ANÁLISE DAS CONDIÇÕES DE ACESSIBILIDADE UR- BANA EM ÁREA CENTRAL DE CURITIBA (PR)
}

ANALYSIS OF THE URBAN ACCESSIBILITY CONDITIONS OF CURITIBA (PR)'S DOWNTOWN AREA

\section{Pillar Muzillo, M.Sc. (UFPR) \\ Cristina de Araújo Lima Correio, Dra. (UFPR)}

\section{Palavras Chave}

Acessibilidade Urbana; Passeios; Área Central; Curitiba

\section{Key Words}

Urban Accessibility; Sidewalks; Downtown Area; Curitiba

\section{RESUMO}

Este artigo tem como objetivo analisar as condições de acessibilidade urbana em recorte da área central do município de Curitiba-Paraná. A partir da revisão teórica sobre o tema, bem como o levantamento de dados em fontes públicas diversas, pôde-se constatar que a acessibilidade urbana não apenas é essencial ao desenvolvimento das atividades humanas, como também se encontra comprometida em diversos pontos da capital paranaense. Por meio da estratégia de Estudo de Caso, foi desenvolvida uma análise qualitativa das condições de acessibilidade urbana de uma das áreas de maior concentração de pedestres do município, priorizando-se aspectos físicos de passeios e guias rebaixadas, tais como regularidade, largura disponível para passagem e inclinações transversal e longitudinal. A partir dos resultados obtidos, pôde-se concluir que a realidade estudada não oferece as condições necessárias para ser considerada acessível, podendo prejudicar pessoas em diferentes condições de saúde.

\section{ABSTRACT}

This paper's purpose is to analyze the conditions of urban accessibility in a selected area of Curitiba-Paraná's downtown area. Through the bibliographic revision of different materials concerning accessibility, as well as the data collection in public sources, it was observed that not only the urban accessibility is essential to the human activities' development, but also that it is damaged in several places of the State of Parana's capital city. Through the Case Study strategy, a qualitative analysis of the accessibility in one of the places with the biggest concentration of pedestrians in the municipality was developed, prioritizing physical aspects of sidewalks and its access ramps, such as regularity, available width for walking, and transversal and longitudinal inclinations. From the results, it was concluded that the studied reality does not offer enough quality to be considered accessible, instead negatively affecting people with different health conditions. 


\section{INTRODUÇÃO}

Este artigo, desenvolvido com base em dissertação de mestrado (Autora, ano), tem como objetivo analisar as condições de acessibilidade urbana nas calçadas de um recorte da área central do município de Curitiba-Paraná. Para o desenvolvimento deste material foram estudados diferentes conceitos, sendo o principal deles o de acessibilidade urbana. Foram considerados, além de sua definição, os atributos que a caracterizam, criando assim condições para a realização da análise que se segue.

A negligência com relação à acessibilidade urbana é uma situação comum a planejadores e gestores de diferentes cidades pelo mundo, sendo ela uma das principais responsáveis pelo estabelecimento de relações de baixa qualidade entre o homem e o espaço urbano, bem como pelos subsequentes obstáculos ao desenvolvimento das atividades sociais a ele vinculados. Segundo a Organização Mundial da Saúde (OMS, 2011), a inexistência ou precariedade de condições externas favoráveis pode prejudicar a adaptação e superação das dificuldades de pessoas com deficiência física ou intelectual, uma vez que o meio físico é decisivo para sua participação e inclusão na sociedade. Pode-se considerar, a partir desse dado, que grande parte das pessoas com deficiência evita o ambiente público por receio de sofrer acidentes ao sair pelas ruas (MASCARÓ e YOSHINAGA, 2005).

$O$ conceito de acessibilidade se constitui, basicamente, na ausência de barreiras para o desenvolvimento das atividades humanas, compreendendo tanto aspectos subjetivos como objetivos, integrados de maneira complementar. Assim, tanto os padrões de comportamento humano, quanto a arquitetura e o urbanismo são essenciais para seu bom funcionamento (SASSAKI, 2009). Segundo a ABNT (2015), a acessibilidade pode ser descrita como a condição física de passeios e calçadas que permite sua utilização por pessoas com diferentes características fisiológicas.

Utilizar o espaço público é direito de todo ser humano, o que torna imprescindível a existência de condições apropriadas para tal. No entanto, são proporcionalmente poucos os espaços no Brasil que apresentem essas estruturas, tal como observado em um levantamento feito pelo Instituto Brasileiro de Geografia e Estatística (2012), o qual constatou problemas como a ausência de pavimentação em $18,3 \%$ dos entornos de domicílios particulares permanentes do país, além da ausência de calçadas (31\%) e do rebaixamento de guia para acesso de pedestres (95,3\%). Em municípios com mais de 1 milhão de habitantes, esses valores atingiram $7,2 \%, 17,1 \%$ e $91,4 \%$, respectivamente, revelando a precariedade de soluções mesmo nas grandes cidades do país.

Estima-se que Curitiba, capital do estado do Paraná, atingiu em 2016 o marco de 1.893.997 habitantes, compondo a oitava maior população das capitais brasileiras. Somado a isso tem-se o fato de que, já em 2010, o município apresentava a sétima maior densidade demográfica do país (IBGE, 2017). O município, no entanto, não está livre dos problemas de acessibilidade urbana encontrados também nos demais municípios brasileiros, tais como passeios com superfícies em condições inadequadas de uso e ausência de guias rebaixadas para pedestres. Um serviço disponibilizado pela Prefeitura Municipal permite que a população registre reclamações relativas a questões como a qualidade dos espaços urbanos. Graças a esse serviço, a Secretaria do Governo Municipal de Curitiba (2015) registrou, entre janeiro de 2010 e novembro de 2015, um significativo número (5.200) de reclamações a respeito de obstruções e prejuízos à qualidade passeios, entre outras questões. Dentre estas, predominaram as queixas sobre a necessidade de construção ou reconstrução de passeios em frente a terrenos baldios ou edificados (55\%) e sobre calçadas danificadas (33\%). Outras questões incluíam barreiras criadas por vegetação indesejada e/ou elementos fixos (10\%), situações ligadas ao mobiliário urbano (0,5\%) e, por fim, às guias rebaixadas $(0,2 \%)$.

É interessante observar a contradição entre teoria e prática no que se refere aos aspectos desta realidade versus a importância dada pelo Plano Diretor Municipal (CURITIBA, 2004) à mobilidade urbana, especialmente no que se refere ao transporte público, um de seus pilares centrais. Por mais consistente que seja a infraestrutura para o deslocamento de veículos em uma cidade, seu uso está também vinculado ao movimento a pé. O ser pedestre não é uma situação permanente do indivíduo, mas sim uma condição temporária que muda no instante do embarque ou desembarque de um veículo, sendo então possível que a dificuldade no caminhar atinja o indivíduo mesmo quando este optar por outros meios de transporte (LARRAÑAGA, 2008).

$O$ recorte desta pesquisa abrange as calçadas de seis quadras do trecho central da Avenida Marechal Floriano Peixoto, uma das maiores e mais importantes vias do sistema de transporte coletivo de Curitiba. A avenida tem origem na região central do município e estende-se até o limite de seu perímetro urbano, ao sul. O trecho central da avenida, em particular, compõe parte de uma área de intenso movimento de pedestres, articulando-se com duas importantes praças do município (Tiradentes e Carlos 
Gomes), e com a Rua XV de novembro, principal rua de uso exclusivamente pedonal de Curitiba.

Considerando a importância dessa avenida para a circulação de pedestres na área, bem como as possíveis consequências de más condições de acessibilidade urbana para transeuntes em diferentes condições de saúde - tais como a falta de acesso a diferentes bens e serviços ali ofertados - questiona-se: Como estão as condições de acessibilidade urbana da Avenida Marechal Floriano Peixoto?

\section{REVISÃO TEÓRICA}

É comum, em diversas cidades, que as decisões de planejamento urbano priorizem questões relacionadas à cidade como um todo antes de se preocuparem com a escala do bairro e com a dimensão humana. Essas experiências, no entanto, têm originado centros urbanos que, apesar do aparente bom funcionamento no todo, apresentam pouca qualidade no que se refere ao espaço vivenciado na escala do homem. Vias públicas que priorizem a fluidez do tráfego de veículos, não necessariamente auxiliam no aprimoramento da qualidade dos espaços urbanos para o pedestre (GEHL, 2009). Lavery et al. (1996), no entanto, consideram essencial para o bom funcionamento da mobilidade urbana a atuação inter complementar entre diferentes escalas, e abordam a jornada pelo espaço urbano por meio de sua analogia com uma corrente (travel chain, ou encadeamento de viagens) na qual cada elo de viagem (travel link), é composto pelo uso de um meio de transporte. Assim, um trajeto composto por diferentes meios de transporte depende do bom funcionamento de todos para ser acessível, inclusive do transporte a pé.

A acessibilidade de um espaço urbano depende da articulação entre a realidade do espaço e a de seu usuário, envolvendo tanto características inerentes ao ser-humano, como sua capacidade de andar ou ver, quanto a qualidade das estruturas que percorre (HALDEN, 2013). As dificuldades enfrentadas nesta relação variam segundo as próprias limitações de cada um (LAVERY et al., 1996), mas pode-se afirmar que existem condições mínimas a serem estabelecidas no projeto de um espaço urbano para que este possa ser utilizado por todos os diferentes públicos, as quais incluem não apenas a qualidade de suas estruturas físicas, como passeios e rampas, como também a densidade e intensidade de acesso a bens e serviços, a variedade de usos do solo e a conectividade de ruas (HANDY, 2002), preferivelmente distribuídos de maneira a atender diferentes exigências em termos de segurança, visibilidade para o público e comunicação com o entorno (GRANT, 2013).
A ideia de acessibilidade pode ser vinculada ao termo em inglês "walkability", livremente traduzido como "caminhabilidade", que é a condição que o espaço oferece para favorecer seu uso pelo pedestre, e que pode ser definida por três fatores: acesso físico, lugares para ir e proximidade. $O$ primeiro diz respeito à qualidade de sua infraestrutura, enquanto o segundo, por sua vez, da presença e variedade de atividades que motivem o deslocamento do pedestre, como restaurantes, escolas, parques, mercados, entre outros. O terceiro, por fim, trata da distância deste serviço com relação ao local de partida do pedestre, como sua residência, por exemplo (LAVEY e HILL, 2014).

Em respeito à constatação das imperfeições que prejudicam a acessibilidade urbana em municípios como Curitiba, cabe se pensar em maneiras de se aprimorar essas condições, tal como proposto por diferentes iniciativas nacionais e internacionais, como a International Charter for Walking, um documento elaborado pela International Federation of Pedestrians (IFP), ou Federação Internacional de Pedestres, que estabelece o compromisso, por parte de planejadores e gestores, de fornecer à população espaços urbanos acessíveis para promover a caminhada. A carta tem como ponto de partida a ideia do deslocamento a pé como um direito universal e de grande importância para a saúde, e tem como princípios o direito a espaços legíveis, ambientalmente agradáveis e utilizáveis pelo maior número possível de pessoas, a fim de promover sua saúde e a interação social (INTERNATIONAL CHARTER FOR WALKING, 2006).

Em termos de projetos arquitetônicos e urbanísticos, merecem ser destacados os princípios do Universal Design (UD) ou Desenho Universal (DU), concebido por Ronald L. Mace em 1988 e cuja proposta se refere ao projeto desenvolvido com o intuito de servir, de modo esteticamente agradável, ao maior número possível de pessoas, independentemente de sua idade ou características físicas, sem o uso de adaptações ou desenhos especializados (MACE, 1988), como elevadores e rampas de uso exclusivo. Conforme anteriormente mencionado, a acessibilidade não depende apenas das condições físicas e psicológicas de um indivíduo, mas também da qualidade do espaço que o cerca. Ou seja, todos podem utilizar plenamente este espaço, desde que este seja adequado para tal. A mobilidade é um elemento em potencial, que depende tanto das características do espaço quanto das do homem: se houver qualquer barreira que este não possa vencer, sua mobilidade será prejudicada, e aquele local já não poderá ser considerado acessível. Degraus, por exemplo, são obstáculos intransponíveis 
para usuários de cadeiras de rodas, mas não necessariamente para pessoas com deficiência visual. Por outro lado, a falta de sinalização sonora em um cruzamento pode comprometer a segurança da pessoa com deficiência visual sem em nada prejudicar o deslocamento do usuário de cadeira de rodas.

O Ministério das Cidades (2006) explica, no entanto, que a falta de conhecimento técnico dos profissionais brasileiros tende a dificultar a implantação do UD no país, tal como é o caso de arquitetos que desistem da ideia por sua preocupação com o possível aumento de custo de suas obras. Além disso, a aceitação do DU pela indústria da construção civil não é unânime, uma vez que muitos criticam-no por ser feito de maneira intuitiva e supostamente desprovida de embasamento teórico científico, devido a seu pouco estudo pela academia. Mesmo estando ainda em desenvolvimento, a proposta poderá vir, no futuro, a ser utilizada como meio para reduzir o desconforto psicológico vivenciado por pessoas com deficiência em situações quotidianas (IMRIE, 2012).

As organizações que buscam contribuir para a criação e manutenção de espaços urbanos acessíveis estão também no Brasil, como é o caso da "Mobilize Brasil", responsável pela campanha "Calçadas do Brasil", cujo objetivo é chamar a atenção da opinião pública para o problema da ausência, má qualidade ou falta de manutenção nas calçadas em diferentes municípios brasileiros, além de estimular a denúncia desses problemas como forma de pressionar as autoridades responsáveis (MOBILIZE.ORG, 2015).

Apesar da maior fragilidade de certos grupos de usuários frente à acessibilidade urbana, cabe lembrar que esta é uma exigência comum a todos os indivíduos em uma cidade, pois o risco de acidentes é comum a todos os que a percorrem, uma vez que, como explica a BCSSA et al. (2004), um ser humano adulto, ao caminhar, não costuma estar atento a seus movimentos, podendo não perceber situações como irregularidades na superfície de um piso, e assim, correndo o risco de acidentes como escorregões e quedas.

A NBR 9050/2015 explica que as calçadas devem poder comportar três faixas de usos: a faixa de serviço, voltada a acomodar peças de mobiliário urbano e vegetação; a faixa livre - ou de passeio - destinada à circulação de pedestres; e a faixa de acesso, que compreende o espaço de passagem da área pública para o interior do lote (Figura 01).

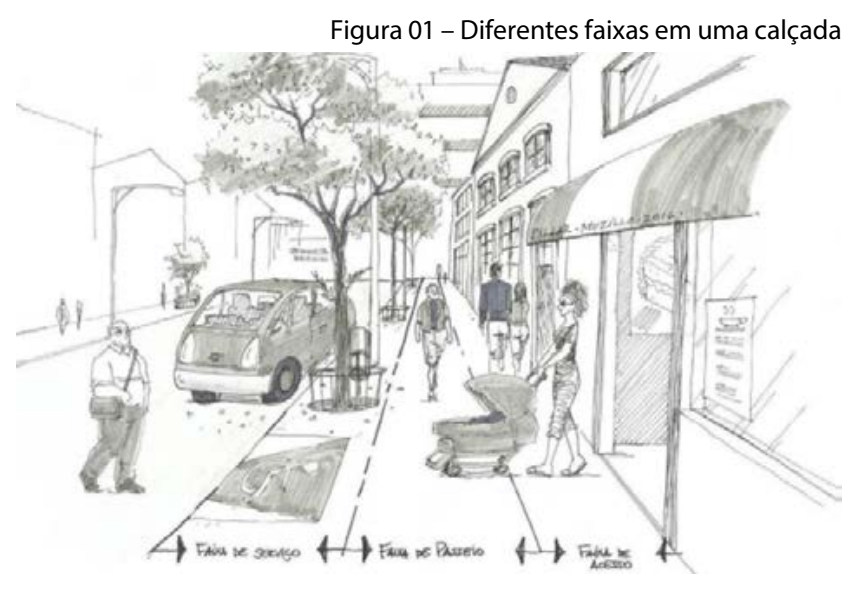

Fonte: Autora (ano)

É importante que essas rotas sejam amplas e lhes ofereçam segurança por meio da iluminação, visibilidade e da clareza de comunicação visual com áreas de recreação, estacionamento e demais estabelecimentos em suas proximidades. A rápida leitura e interpretação do espaço contribui não somente para seu uso quotidiano como também para auxílio à população em caso de emergências e para a prevenção de atividades criminosas (KANE et al., 2002).

A largura de uma passagem apresenta para o pedestre também importância psicológica, interferindo em sua sensação de liberdade de movimento, mas, preferivelmente, sem lhe causar a sensação de desamparo comum a locais excessivamente amplos. Pessoas idosas, com deficiência, com crianças ou transportando carrinhos de bebê ou de compras, estão entre os que apresentam maior necessidade de amplitude espacial, uma vez que podem ter dificuldades de acompanhar o ritmo de caminhada dos demais pedestres (GEHL, 2009).

$\mathrm{O}$ ato de caminhar pode ser descrito como um sistema de forças no qual interagem, simultaneamente, fatores inerentes ao ambiente e ao ser-humano, tais como aspectos construtivos, velocidade do movimento, condições de equilíbrio corporal da pessoa e a natureza do solo (YABIKU, 2006). Regularidade e textura da superfície, resistência estrutural e ao congelamento e capacidade de saturação de água nos poros do material são alguns dos aspectos que merecem atenção no processo de projeto e execução da calçada. Além disso, devem ser evitados riscos como os de quedas e escorregões, ou trepidações de cadeiras de rodas, trepidações (LAVERY et al., 1996).

A NBR 9050/2015 não especifica valores de referência para avaliar se uma superfície é mais ou menos escorregadia, embora estabeleça que deve ser "firme, estável e antiderrapante sob qualquer condição" (p. 39) e não provocar trepidações em equipamentos como cadeiras de rodas 
e carrinhos de bebê. Um material de revestimento em particular, trabalhado no estudo de caso deste artigo, é o mosaico português, uma técnica de pavimentação que consiste em acumular e conjugar pequenas pedras de calcário e o basalto de formatos irregulares, para compor padrões decorativos nas cores branca, preta, castanha ou vermelha (PEREIRA, SILVA e FONSECA, 2015). Existem divergências entre a Prefeitura Municipal e o Ministério Público sobre o uso do mosaico português em calçadas em Curitiba, uma vez que, enquanto o MP considera-o derrapante e potencialmente perigoso, a prefeitura defende-o por ser elemento característico do patrimônio histórico do município (VICENTE, 2006).

Outro item que merece atenção no estudo da acessibilidade urbana é a inclinação das calçadas, definida pela razão entre a diferença de cota e a distância horizontal entre dois pontos de uma mesma superfície e ocorrendo em dois sentidos diferentes da via, longitudinal e transversal. Cada um apresenta seu próprio valor máximo, sendo $5 \%$ para a longitudinal e $3 \%$ para a transversal (ABNT, 2015), os quais, por motivos de segurança e de facilidade para o deslocamento, não devem ser ultrapassados: uma calçada com inclinações excessivamente altas oferece, para um usuário de cadeira de rodas, por exemplo, maior dificuldade de manuseio da cadeira e de deslocamento, o que aumenta a possibilidade de sofrer acidentes.

\section{ASPECTOS METODOLÓGICOS}

Esta pesquisa foi desenvolvida por meio de uma abordagem qualitativa na qual se buscou a verificação de condições de acessibilidade urbana das calçadas de um recorte delimitado na área central de Curitiba-Paraná. Devido ao vínculo indissociável entre o objeto estudado e a realidade, bem como à subsequente impossibilidade de controle, sob o ponto de vista da pesquisa científica, das variáveis envolvidas com o objeto estudado, optou-se pela estratégia do Estudo de Caso. Este artigo partiu de um projeto de pesquisa rígido, no qual foram especificados parâmetros de análise para organização e a avaliação da realidade encontrada, visando qualificar as condições de acessibilidade urbana na área em questão. Tal como recomendam Robson (2002) e Yin (2010), múltiplas fontes de evidência foram utilizadas, entre as quais documentos, mapas e dados da Prefeitura Municipal, registros, artigos, observação direta e artefatos físicos verificados in loco.

A partir das questões levantadas durante a revisão teórica, com enfoque nos elementos físicos que definem a acessibilidade urbana, foi delimitado um recorte espacial, em Curitiba, que apresentasse intenso movimento de pedestres e que exigisse aprimoramento de suas condições de acessibilidade. A escolha deste recorte se deu com base na consideração a parâmetros urbanísticos do município associados as suas maiores demandas em termos de acessibilidade urbana, a saber: a) Densidade demográfica e uso do solo; b) Hierarquia viária; c) Número de linhas de ônibus no local; e d) Importância, para o PDM, da via onde se definiu o recorte. Esses critérios foram escolhidos com base em artigos internacionais relacionados ao tema.

A densidade urbana, em primeiro lugar, afeta o volume de passageiros que fazem uso do sistema de transporte público de um município, de modo que quão maior a densidade, maior o uso desse sistema (NEWMAN, 1989 apud COOKE e BEHRENS, 2014). Segundo o IBGE (2010) apud IPPUC (2015), o Centro, bairro onde se situa o trecho estudado, apresenta desde 1970 a maior densidade urbana de Curitiba. Quanto ao uso do solo, utilizou-se como referência a ideia de que certos usos, ao se complementarem, produzem espaços que favorecem a caminhabilidade, como é o caso da relação entre comércio e residência (MOUDON e HESS, 2000), presentes na área estudada. O Centro de Curitiba, além de articular essas funções para seus habitantes mais próximos, atrai também pessoas de outras áreas da cidade, uma vez constatada a quantidade e variedade de serviços nele disponíveis.

Quanto à hierarquia viária, foram consideradas as vias de maior relevância para a estruturação e organização dos fluxos da cidade, especificamente no que se refere ao sistema de transporte coletivo municipal, devido à maior possibilidade de atraírem pedestres. Em Curitiba, as vias estruturantes desse sistema- no caso os eixos estruturais - são, de acordo com o Plano Diretor Municipal (2004), os responsáveis por canalizar o tráfego das diferentes regiões da cidade, servindo também de base para o adensamento populacional. Juntamente à hierarquia viária, foi definido como critério o número de linhas de ônibus que passam pelo local, visto que sua maior intensidade de uso poderia atrair um número maior de pessoas, vindas de diferentes áreas da cidade, do que locais com poucas linhas. As linhas de ônibus respectivas a cada uma das vias propostas para estudo foram encontradas a partir de seus itinerários, disponíveis para download na página da instituição responsável (URBS, 2015).

Após a seleção do local de estudo, foram feitas a observação e o levantamento fotográfico de suas condições de acessibilidade urbana, a partir dos quais foram elaborados mapas e quadros de análise para sua avaliação. Foram consideradas características projetuais e construtivas de calçadas e guias rebaixadas dentro da área em 
questão, buscando-se verificar em que medida atendiam às necessidades da população em termos de acessibilidade urbana, como previsto pela NBR 9050/2015. Os principais pontos analisados foram: a) Inclinação longitudinal e transversal das calçadas; b) Regularidade do piso, em termos de patologias como ondulações, fissuras e peças soltas; c) Largura para passagem de pedestres e presença de obstáculos - como peças de mobiliário urbano instaladas em local inapropriado; e d) Guias rebaixadas, considerando a regularidade de sua superfície e elementos de comunicação (no caso, sinalização visual e tátil para sinalizar a presença da rampa). $O$ estudo dessas questões foi feito com base na revisão bibliográfica de autores como Gehl (2009), Grant (2013), Handy (2002) e Lavey e Hill (2014).

$\mathrm{O}$ objeto selecionado para análise situa-se na área central do município de Curitiba-Paraná e compreende um trecho de seis quadras da Av. Marechal Floriano Peixoto (Figura 02), dentro da área com maior movimento de pedestres. A unidade de análise definida para esta pesquisa compreende calçadas e guias rebaixadas para pedestres em cruzamentos de vias. Como forma de promover maior especificidade durante o levantamento e análise dos dados, o recorte foi subdividido conforme as quadras ali presentes.

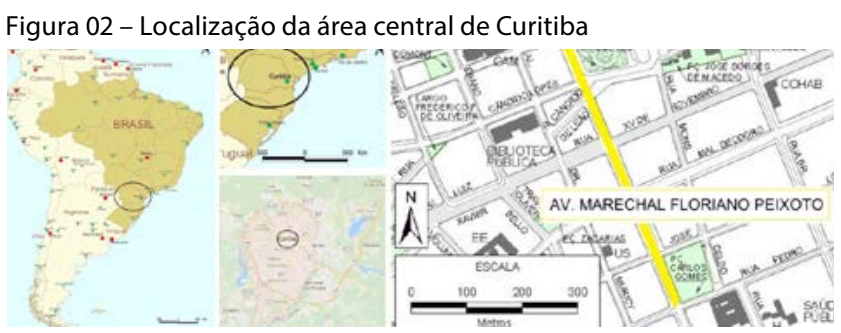

Fonte: Adaptado de IPPUC (2017) e Google (2017)

Os elementos estudados foram avaliados então a partir de um sistema de notas, elaborado a partir da atribuição de pesos para as diferentes situações encontradas. A escolha pela utilização de critérios de nota teve referência nos trabalhos de Duarte e Cohen (2006), Machado e Lima (2015) e Mobilize.org (2015). Cada um destes trabaIhou com a definição de notas correspondentes a situações específicas referentes a cada critério, contribuindo para o desenvolvimento do sistema de avaliação utilizado neste estudo. Cada aspecto foi classificado dentro de um sistema de nota definido conforme as características dos locais estudados (e.g.: largura para passagem e inclinação transversal e longitudinal em satisfatória ou insatisfatória conforme estivessem ou não dentro dos valores previstos pela norma; regularidade de superfície e condições das rampas para pedestres, conforme fossem suas irregularidades). Assim como nos trabalhos de Duarte e Cohen (2006) e Machado e Lima (2015), o recorte estudado foi subdividido, e as avaliações feitas com a ajuda de tabelas. Não foram realizadas, no entanto, entrevistas com usuários dos espaços estudados ou com profissionais responsáveis por sua definição, e tampouco realizados os mesmos procedimentos de cálculos presentes nos trabalhos de referência. Assim, os tópicos selecionados como critérios de análise da realidade estudada pela pesquisa foram:

a) Inclinação longitudinal da calçada: Para se obter esses dados, utilizou-se como base um arquivo na extensão .DWG, baixado na página do IPPUC e contendo as curvas de nível de cinco em cinco metros, o qual foi aberto no software ArchiCAD ${ }^{\circledR}$ e modelado em 3D (Figura 03) para criar cortes e um volume de características próximas às da realidade da área em questão.

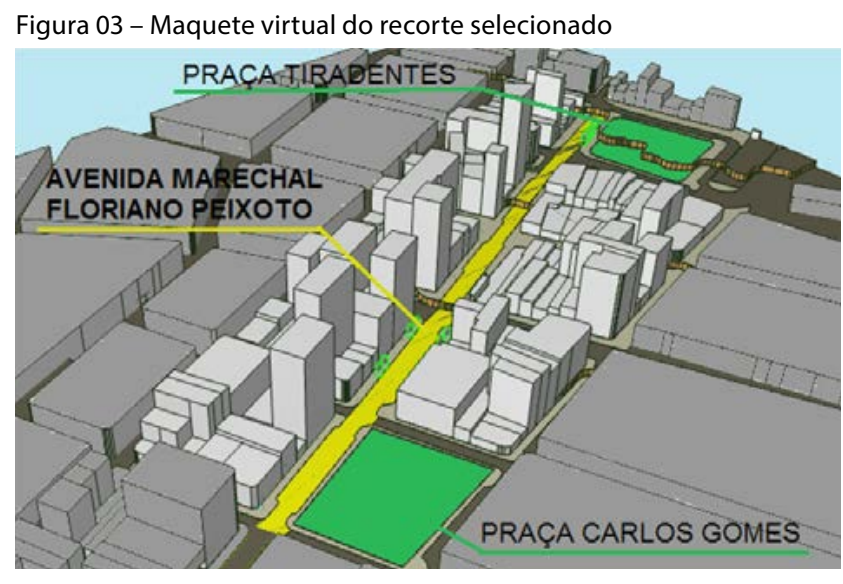

Fonte: Autores (2017)

b) Inclinação transversal: medida com o auxílio de medidor de nível eletrônico Skil ${ }^{\circledR} 8201-C L$ F012 K63 010, que funciona a partir da projeção de feixes de lasers em linhas verticais e horizontais no piso e nas paredes próximas, possibilitando a mensuração de diferentes distâncias com a ajuda de uma trena metálica. O laser, projetado perpendicularmente à testada, marcou a posição e cota do equipamento com relação às paredes e ao piso. Em cada posição estudada foram medidos esses valores, a partir dos quais foi possível elaborar cortes no software AutoCAD ${ }^{\circledR}$, para sua visualização (Figura 04).

Figura 04 - Representação esquemática do aparelho utilizado

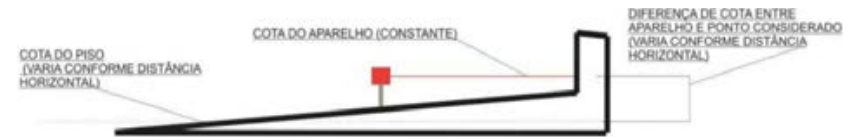

Fonte: Autora 
c) Regularidade do piso e estado de conservação: a obtenção desses dados foi feita por meio de levantamento in loco dos materiais ali utilizados e de suas principais patologias: fissuras, ondulações, buracos e peças soltas.

d) Largura da faixa livre e presença de obstáculos: medidas in loco com trena metálica, manuseada por duas pessoas. Foram verificadas as larguras totais da calçada de cada trecho e a mínima largura disponível para passagem, caso estivessem presentes peças de mobiliário como postes, lixeiras, bancos, placas ou árvores (Figura 05). Peças instaladas em posições que interrompessem a faixa de passeio foram considerados obstáculos.

Figura 05 - Largura para passagem em trecho do recorte selecionado

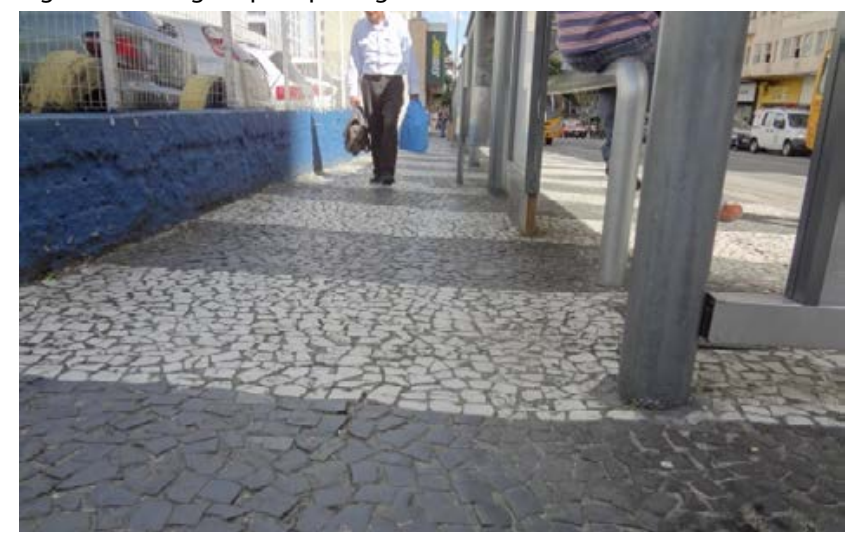

Fonte: Autora

e) Rebaixamento de guias para pedestres: Os critérios adotados para avaliação deste aspecto foram similares aos utilizados na avaliação dos passeios - considerando a presença de ondulações, fissuras ou peças soltas na superfície - incluindo também obstáculos que pudessem interromper a passagem do pedestre (Figura 06).

Figura 06 - Irregularidade encontrada em guia rebaixada

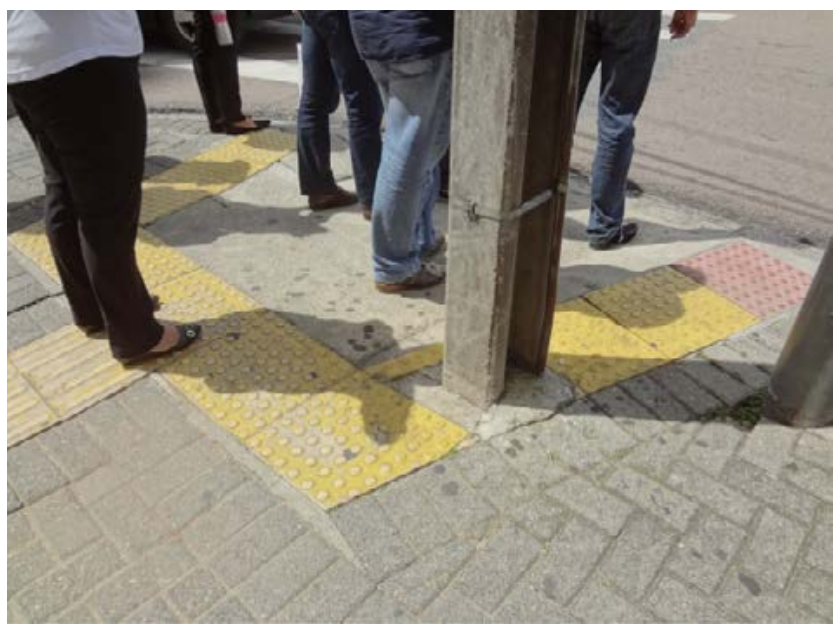

Fonte: Autora
Aspectos como inclinações, que apresentam valores mensuráveis, receberam nota conforme atendessem ou não às exigências da $A B N T$, ou seja, estivessem dentro do limite considerado aceitável. Irregularidades de superfície, por outro lado, foram levantadas visualmente e consideradas a partir de sua presença ou predominância na área estudada.

\section{RESULTADOS}

Este artigo procurou ressaltar aspectos da acessibilidade urbana relacionados a constituição física de calçadas e guias rebaixadas em recorte na área central de CuritibaParaná. Assim, apesar de não serem essas as únicas condições que definem a qualidade de um espaço urbano, optou-se pela restrição de sua esfera de abrangência, possibilitando assim maior profundidade ao estudo. A questão da acessibilidade em Curitiba tem sido discutida pelo poder municipal desde os anos 1980, tendo também como enfoque as necessidades de pessoas com deficiência, sobretudo com relação a seu acesso ao transporte público. Apenas em 2004 a acessibilidade passou a ser prevista pelo Plano Diretor Municipal de Curitiba, mas somente com sua revisão, em 2014, é que passou a contar com um tópico específico sobre a circulação não motorizada, defendendo princípios do Desenho Universal (DU) e a equidade no uso do espaço público de circulação.

O recorte da Avenida Marechal Floriano Peixoto escoIhido para estudo é compreendido pela Zona Central (ZC), tendo como usos permitidos a habitação, o comércio, o uso comunitário e industrial com porte inferior a $100 \mathrm{~m}^{2}$. Na direção sudeste, esta avenida se torna eixo do Setor Estrutural (SE), voltado à canalização do transporte coletivo municipal e ao prolongamento das funções previstas para a ZC. Os usos dos imóveis nesta área compreendem bancos, lanchonetes, comércio de roupas e acessórios, entre outros, o que a torna atraente ao pedestre, promovendo a intensificação de seu uso e contribuindo para o aprimoramento de sua caminhabilidade. Em termos de equipamentos urbanos, foi levantada a presença de mais de 25 pontos de ônibus em um raio de 250 metros, a contar do eixo da via.

A Figura 07 mostra, em amarelo, o recorte da Av. Mal. Floriano Peixoto selecionado para estudo. Nele estão marcadas as divisões em seis diferentes trechos, conforme anteriormente mencionado. Cada marcação em vermelho corresponde a uma subdivisão, marcada por números, e cujo estudo foi feito em ambos os lados da rua, chamados de Ida (sentido Praça Tiradentes - Praça Carlos Gomes) e Volta (sentido Praça Carlos Gomes - Praça Tiradentes). 
Figura 07 - Delimitação e divisão da área estudada em trechos

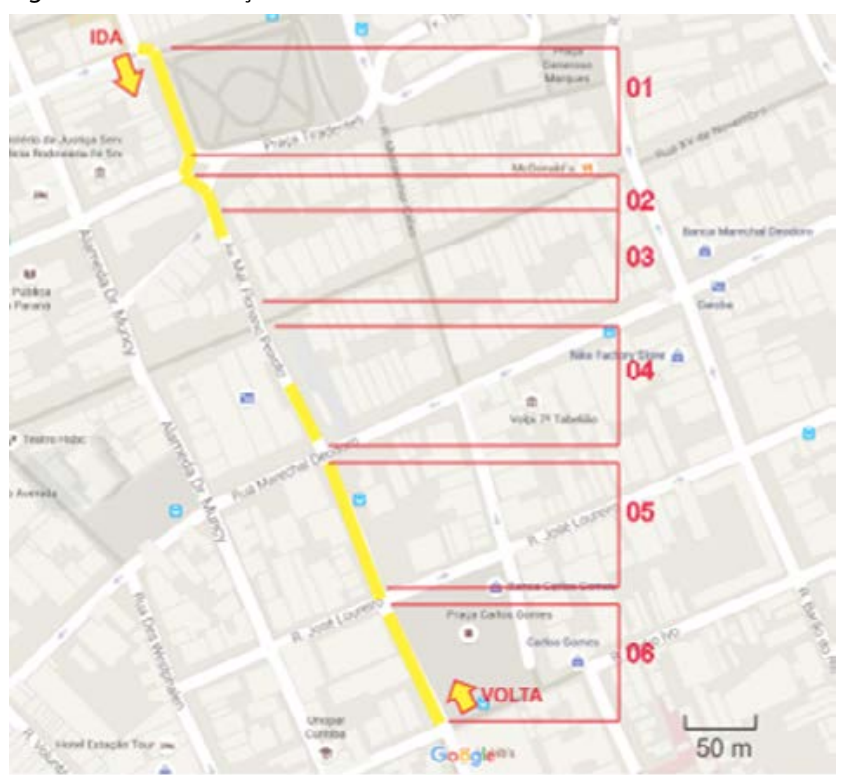

Fonte: Autora

Dentro do conceito de caminhabilidade descrito por Grant (2013), a área estudada apresenta boa conectividade, oferecendo variadas possibilidades em termos de caminhos: a extensão longitudinal de cada trecho varia entre 70 e 100 metros, tornando-os pouco cansativos em termos de perspectiva, permitindo a conectividade com as demais ruas e a fácil mudança de rota caso o pedestre assim deseje. Os valores encontrados para a inclinação longitudinal variam de quadra a quadra, conforme mostrado na Tabela 01:

Tabela 01 - Inclinações máximas para cada trecho estudado Valores encontrados (\%) para inclinaçס̋es longitudinal e transversal

\begin{tabular}{l|l|l|l|l|l}
\hline IDA & Longitudınal & $\begin{array}{l}\text { Transversal } \\
\text { Máx }\end{array}$ & VOLIA & Longitudınal & $\begin{array}{l}\text { Transversal } \\
\text { Máx }\end{array}$ \\
\hline 01 & 3 & 8,7 & 01 & 3 & 10,2 \\
\hline 02 & 2,8 & 2 & 02 & 3,4 & 0,7 \\
\hline 03 & 4 & 5 & 03 & 3,4 & 5,2 \\
\hline 04 & 3 & 5,5 & 04 & 3,2 & 9 \\
\hline 05 & 1,5 & 3,5 & 05 & 1,6 & 3 \\
\hline 06 & 0,8 & 5 & 06 & 0,9 & 4,4 \\
\hline
\end{tabular}

Fonte: Autora

O valor máximo permitido para a inclinação longitudinal de passeios, ainda de acordo com a norma, é de 8,33\%, o que significa que, em teoria, todas as inclinações observadas podem ser consideradas satisfatórias. Questionase, no entanto, se esses seriam mesmo adequados, em termos de esforço realizado pelo pedestre - em especial usuários de cadeira de rodas - e se pisos com diferentes aderências não tornariam necessária a revisão destes valores. A NBR 4050/2015 apresenta determinações para pisos com declividades superiores a 5\%, valor a partir do qual passam a ser consideradas rampas. No entanto, como se pôde observar, este não foi o caso.

Com relação à inclinação transversal, os valores medidos dentro de cada trecho apresentaram variações, uma vez que os perfis das secções de uma mesma quadra variavam. Foi observado que, mesmo em trechos cujas diferenças de cota entre a guia e a testada do lote foram pouco expressivas, a presença de afundamentos no terreno criava, entre um ponto e outro, condições de inclinação mais acentuadas do que o considerado aceitável pelas normas. Pode ser observado que a maioria dos trechos considerados apresentou condições insatisfatórias, ultrapassando o valor máximo de $3 \%$ considerado aceitável.

A regularidade de superfície tanto das calçadas como das rampas foi avaliada com base na observação de ondulações, fissuras, peças soltas e desníveis. No que se refere às calçadas, este aspecto foi qualificado como negativo ao longo de todo o recorte selecionado, dada a presença desses defeitos ao longo de todo o caminho, ainda que em proporções variadas. Foram percebidas diferenças significativas entre a regularidade das calçadas pavimentadas em mosaico português e a das pavimentadas em concreto intertravado. O Gráfico 01 mostra os resultados do levantamento sobre a regularidade das superfícies nas calçadas, no qual se pode perceber a diferença entre a frequência de cada irregularidade dentro de cada trecho do recorte escolhido. Gráfico 01 - Resultados do levantamento da regularidade de superfície
das calçadas no recorte estudado

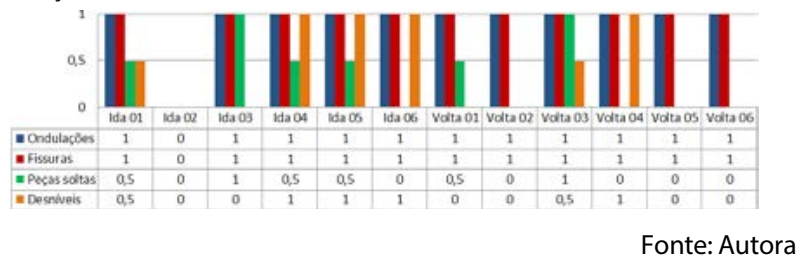

A frequência observada varia de 0 (nenhuma) a 1 (maior parte ou extensão total do trecho), sendo que o valor intermediário de 0,5 remete a ocorrências pontuais, mas que não ultrapassam a metade do trecho considerado. Um aspecto que pode ser destacado é o fato de que, em diversos locais onde havia fissuras, o passeio demonstrava também afundamento, sugerindo que sua origem pode estar relacionada à compactação progressiva e desigual do revestimento sobre terreno, causadas pelo 
movimento de pedestres na área, ou a alterações em suas condições topográficas.

Quanto às guias-rebaixadas, foi constatado que estas, em sua maioria apresentava problemas, sendo os mais recorrentes as ondulações e fissuras em sua superfície, além da falta de sinalização visual em sua superfície e tátil em seu perímetro. 0 gráfico 02 sintetiza a frequência com que foram observadas as irregularidades nos trechos estudados. Cabe mencionar que os valores de 0 a 1 foram adaptados para compreender o fato de que havia mais de uma guia rebaixada para cada trecho de ida ou volta: caso a irregularidade estivesse em todas ou na maioria das guias, o aspecto receberia valor 1 . Se estivesse presente em apenas uma, ou em menos da metade delas, receberia 0,5 e, se estivesse ausente, zero.

Gráfico 02 - Resultado do levantamento da regularidade de superfície nas guias rebaixadas do recorte

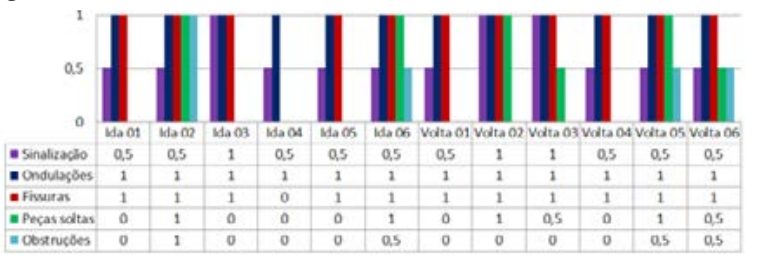

Fonte: Autora

Os trechos 02,03 e 06 foram os que apresentaram as piores condições de uso, sendo que o primeiro contava com um poste em concreto interrompendo uma de suas rampas, o segundo, afundamentos e irregularidades mais acentuadas do que nos demais casos, e o terceiro áreas com piso quebrado formando cacos e peças soltas, espaIhados pelo chão.

Quanto à largura disponível para passagem, esta foi verificada como suficiente na maior parte da área selecionada, sendo pouco numerosas as situações em que a presença de obstáculos tenha interrompido ou reduzido a faixa de passeio. As peças de mobiliário e vegetação encontravam-se em sua devida faixa, de. No trecho ida 01 esta interrupção se deu por conta da presença de abrigos de ônibus e postes de luz, que criavam uma faixa de passeio com largura de $1,76 \mathrm{~m}$, ainda aceitável pelas normas da ABNT. Já no trecho 02 , o obstáculo encontrado foi um ponto de táxi, que reduzia a largura total disponível para o pedestre de 4,0m para menos de 2,0m. Embora a ABNT defina o valor mínimo de $1,20 \mathrm{~m}$ como necessários para a passagem de pessoas que utilizem ou não a cadeira de rodas, o abrupto estreitamento pode comprometer o fluxo de pessoas, sobretudo no caso da passagem de pessoas que caminham em direções opostas, causando assim maiores transtornos para o pedestre. Além disso, nenhuma das peças estava sinalizada com piso tátil, o que poderia ser um empecilho para pessoas com deficiência visual.

Como forma de se finalizar a análise dos resultados, se verifica que, embora bem estruturado em termos de equipamentos urbanos ligados ao transporte e de conexão com ruas em suas proximidades, o recorte estudado apresenta condições insatisfatórias de qualidade em suas calçadas guias rebaixadas para pedestres. A presença de irregularidades ao longo de toda sua extensão - tanto em passeios como em guias rebaixadas, além da inclinação transversal excessiva de certos trechos (especialmente 01 e 04), são potencialmente prejudiciais à segurança do pedestre, podendo ocasionar acidentes de diversas intensidades.

Cabe mencionar que, embora a maior parte das calçadas estudadas fosse revestida com mosaico português - técnica polêmica por seu mau desempenho em termos de acessibilidade - é possível que as irregularidades encontradas sejam fruto de falhas de projeto e execução do revestimento, bem como resultado de sua utilização contínua desde sua inauguração até os dias de hoje. A partir desses resultados, pode ser evidenciada a necessidade de um projeto de revitalização dessa área, acompanhado de sua constante manutenção.

\section{CONCLUSÕES}

A acessibilidade urbana é uma condição essencial a qualquer cidade, cujos problemas de uma área podem se repetir em outra. Sendo assim, é possível se pensar em diretrizes gerais capazes de aprimorar a realidade urbana brasileira, tais como políticas públicas voltadas às condições de acessibilidade, com participação popular, tais como: a criação de cursos de atualização para profissionais da construção civil, a intensificação da fiscalização sobre obras de construção civil públicas e privadas, o incentivo do desenvolvimento de pesquisas e trabalhos acadêmicos na área, e o maior diálogo entre o poder público e a população.

Ao longo deste estudo, foi constatada uma tendência de o problema da acessibilidade urbana ser tratado pela sociedade como um item de interesse quase exclusivo de pessoas com deficiência ou mobilidade reduzida. No entanto, os problemas ligados ao uso de calçadas de má qualidade podem atingir a qualquer pessoa, de modo que a responsabilidade em se criar espaços acessíveis deve considerar a todos, e não apenas a uma parcela da população. Assim como propõe o DU sobre a abrangência e universalidade das soluções de acessibilidade urbana, defende-se aqui que ela não mais seja abordada como um elemento 
"extra" do projeto, mas sim que dele faça parte desde sua concepção. A acessibilidade urbana é um direito de toda a população, de modo que, é importante, para seu aprimoramento, que o conceito deixe de ser tratado como a necessidade de um público específico (Secretaria Especial de Direitos da Pessoa com Deficiência, 2015).

O espaço urbano tanto reflete quanto condiciona encadeamentos específicos de eventos e ideias associados a fenômenos sociais próprios do contexto social a ele vinculado (CORRÊA, 2005). A construção do espaço urbano reproduz, portanto, as principais ideias e valores de uma sociedade, que dá maior ou menor importância a determinadas questões conforme seus diferentes graus de prioridade. No caso da acessibilidade não poderia ser diferente: seu aprimoramento requer, antes de mais nada, uma mudança de pensamento e de perspectiva pela sociedade.

\section{AGRADECIMENTOS}

Os autores agradecem à Coordenação de Aperfeiçoamento de Pessoal de Nível Superior (CAPES) e ao Programa de Pós Graduação em Engenharia de Construção Civil da Universidade Federal do Paraná (PPGECC-UFPR) pelo apoio e incentivo no desenvolvimento desta e de outras pesquisas, bem como pelas bolsas de estudo e infraestrutura disponibilizadas.

\section{REFERÊNCIAS}

Associação Brasileira de Normas Técnicas (ABNT). NBR 9050: Acessibilidade a edificações, mobiliário, espaços e equipamentos urbanos. Disponível em: <http://www. pessoacomdeficiencia.gov.br/app/sites/default/files/ arquivos/\%5Bfield_generico_imagens-filefield-description\%5D_24.pdf>. Acesso em 30.mai.2017.

BCSSA (British Columbia School Safety Association) / BCPSEA (British Columbia Public School Employer's association)/WCB (Workers' Compensation Board of British Columbia). Expert panel on reducing the number of slips/falls is school districts facilities. Columbia, 2004. Disponível em: <http://www.bcpsea.bc.ca/documents/ expertpanel3.pdf>. Acesso em: 21.jun.2017.

CURITIBA. Lei Ordinária n. 11.266/2004: “Dispõe sobre a adequação do Plano Diretor de Curitiba ao Estatuto da Cidade - Lei Federal no 10.257/01, para orientação e controle do desenvolvimento integrado do Município". Disponível em: <https://www.cmc.pr.gov.br/pd_plano_ diretor.php>. Acesso em: 21.jun.2017.
DUARTE, C. R., COHEN, R. Proposta de metodologia de avaliação da acessibilidade aos espaços de ensino fundamental. In: Anais NUTAU 2006: Demandas Sociais, Inovações Tecnológicas e a Cidade. São Paulo, USP: 2006. Disponível em: <http://www.proacesso.fau.ufrj.br/artigos/Acessibilidade $\% 20$ em $\% 20$ Escolas $\% 20$ NUTAU\%20 2006.pdf $>$. Acesso em: 21.jun.2017.

GEHL, J. La humanización del espacio urbano. $5^{\mathrm{a}}$ ed. Barcelona, Editorial Reverté S.A, 2009.

GRANT, B. Getting to great places: how better urban design can strengthen San Jose's future. In: Spur report. San jose, 2013. Disponível em: <http://www.spur.org/publications/spur-report/2013-12-12/getting-great-places>. Acesso em: 20.abr.2016

HALDEN, D. The use and abuse of accessibility measures in UK passenger transport planning. Disponível em: <http://dhc1.co.uk/content/useandabuseonline.pdf $>$. Acesso em: 10.mai.2016.

HANDY,S.L.,BOARNET,M.G.,EWIG, R., KILLINGSWORTH, R. E. How the built environment affects physical activity: views from urban planning. In: American Journal of Preventive Medicine. N. ${ }^{\circ} 23$, vol. 2. p. 64 - 73. Elsevier Science, 2002. Disponível em: <http://www.ajpmonline.org/article/S0749-3797(02)00475-0/pdf>. Acesso em: 21.jun.2017.

IBGE. Cidades. Disponível em: <http://www.cidades. ibge.gov.br>. Acesso em 28.mai.2017.

IMRIE, R. Universalism, Universal Design and equitable Access to the built environment. In: Disability \& Rehabilitation, n. ${ }^{34}$, vol.10, Informa UK, 2012. Disponível em: < 10.3109/09638288.2011.624250 >. Acesso em 29.fev.2015.

IPPUC. Bairros mais densos de Curitiba. In: Análise do Censo. Disponível em: <http://ippuc.org.br/visualizar.php?doc=http://admsite2013.ippuc.org.br/arquivos/ documentos/D356/D356_003_BR.pdf>. Acesso em: 31.mai.2017.

Instituto Brasileiro de Geografia e Estatística IBGE. Censo demográfico 2010: Características urbanas do entorno dos municípios. IBGE, Rio de Janeiro, 2012. Disponível em: <http://biblioteca.ibge.gov.br/ 
visualizacao/periodicos/96/cd_2010_entorno_domicilios. pdf >. Acesso em: 05.ago.2015.

International Federation of Pedestrians (IFP). International Charter for Walking, 2006. In: WALK21 International Conference, 2006. Disponível em: < http:// www.walk21.com/>. Acesso em: 21.jun.2017.

KANE, G, HEANEY, G, EWART, K, MCALISTER, B. Developing an accessibility appraisal model for the external environments of housing estates. In: Facilities, vol. 20, n. 3/4, p.104-112. Emerald Sight, 2002. Disponível em: <http://dx.doi.org/10.1108/02632770210423830>. Acesso em: 01.jul.2015.

LARRAÑAGA, A.M.Análise do padrão comportamental de pedestres. Dissertação de mestrado. Programa de pós-graduação em Engenharia de Produção da UFRS. Porto Alegre, 2008. Disponível em: < https://www.lume. ufrgs.br/bitstream/handle/10183/15294/000677736. pdf?sequence $=1>$.

LAVERY, I. DAVEY, S. WOODSIDE, A. EWART, K. The vital role of street design and management in reducing barriers to older peoples' mobility. In: Landscape and Urban Planning. vol.35, n. 2 e 3. P. 181-192. Elsevier, 1996. Disponível em: <http://www.sciencedirect.com/science/ article/pii/016920469600309X>. Acesso em: 25.abr.2015.

LAVEY, J. HILL, J. What is walkability?. Disponível em: <http://communitybuilders.org/walkability/>. Acesso em 20.abr.2016.

MACE, R. L. Ronald L. Mace. Disponível em: <http:// www.universaldesign.com/index.php?option=com_content\&view=article\&id=88:rona Id=-I-mace-faia\&catid2196:universal-design\&ltemid=2931>. Acesso em: 06.out.2014

MACHADO, M. H., LIMA, J.P. Avaliação multicritério da acessibilidade de pessoas com mobilidade reduzida: um estudona região central de Itajubá (MG). In: Urbe: Revista Brasileira de Gestão Urbana. V. 07, no. 03. Set/dez. 2015. Disponível em: <http://www.scielo.br/pdf/ urbe/v7n3/2175-3369-urbe-2175-3369007003AO08.pdf >. Acesso em 30.mai.2016.

MASCARÓ, J.L. YOSHINAGA, M. Infra-estrutura urbana. $1^{\text {a }}$ ed. Porto Alegre, Masquatro Editora, 2005.
SASSAKI, R. K. Inclusão: acessibilidade no lazer, trabalho e educação. In: Revista Nacional de Reabilitação (Reação). São Paulo, Ano XII, mar./abr. 2009, p. 10-16.

MINISTÉRIO DAS CIDADES. Implementação do Decreto no..296/04 para a construção da cidade acessível. In: Programa brasileiro de acessibilidade urbana Brasil acessível. Caderno 3. Disponível em: < http://www. faders.rs.gov.br/uploads/1310575361BrasilAcessivelCaderno03.pdf > . Acesso em: 22.set.2015.

MOBILIZE.ORG. Divisão modal (\%) cidades. Disponível em: <http://www.mobilize.org.br/midias/estatisticas/divisao-de-modais-por-cidades-ii.png>. Acesso em: 13.out.2015

MOUDON, A. V., HESS, P. Suburban Clusters. In: Journal of the American Planning Association, V. 3, n. 3. P.46-55. Taylor \& Francis, 1999. Disponível em:< http://www.tandfonline.com/doi/abs/10.1080/01944360008976105>. Acesso em 31.mai.2017.

NEWMAN, P.W.G. Cities and automobile dependence: a sourcebook. Gower, Aldershot In: COOKE, S. BEHRENS, R. A comparative analysis of the relationship between public transport and land use characteristics. In: Proceedings of the 33rd Southern African Transport Conference (SATC, 2014). Pretoria, CE Projects, 2014. Disponível: <http://hdl.handle.net/2263/45522 >. Acesso em: 21.jun.2017.

Organização Mundial da Saúde (OMS). World report on disabilities. Disponível em: <http://www.who. int/disabilities/world_report/2011/en/>. Acesso em 31.mai.2017.

PEREIRA, R., SILVA, R., FONSECA, N. A calçada portuguesa. Disponível em: < http://www.archdaily.com. br/br/763989/a-calcada-portuguesa>. Acesso em: 05.fev.2016.

ROBSON, C. Real world research: a resource for social scientists and practitioner-researchers. 2 ed. Malden: Blackwell Publishers, 2002.

SECRETARIA ESPACIAL DE DIREITOS DA PESSOA COM DEFICIÊNCIA (SEDPCD). Entrevista concedida a Autora. Curitiba, 29 abril. 2015. 
SECRETARIA DO GOVERNO MUNICIPAL. Relatório Acessibilidade - protocolos. Curitiba, 2015. Documento obtido por e-mail.

URBANIZAÇÃO DE CURITIBA S/A (URBS). Itinerários. Disponível em: <https://www.urbs.curitiba.pr.gov.br/ transporte/itinerarios $>$. Acesso em 21.jun.2017.

VICENTE, M. X. Petit-pavé é a pedra da discórdia do calçamento curitibano: especialistas mostram argumentos contrários e a favor do revestimento que virou polêmica em Curitiba. In: Gazeta do Povo. Disponível em: < http://www.gazetadopovo.com.br/vida-ecidadania/petit-pave-e-a-pedra-da-discordia-do-calcamento-curitibanoa8zv7row1phqlxkmse5i2lk5q>. Acesso em: 17.ago.2015

YABIKU, L. Pedestre: modalidade de transporte na cidade - uma visão ergonômica. Tese de doutorado. Faculdade de Arquitetura e Urbanismo da Universidade de São Paulo, área de Tecnologia da Arquitetura. São Paulo, 2006. Disponível em: <10.11606/T.16.2006.tde18112010-114629>. Acesso em: 21.jun.2017.

YIN, R. Estudo de caso: planejamento e métodos. 2 ed. Bookman, Porto Alegre, 2010. 